\title{
Progressive multifocal leukoencephalopathy: new concepts
}

Leucoencefalopatia multifocal progressiva: novos conceitos

Marco A. Lima

\begin{abstract}
Progressive multifocal leukoencephalopathy (PML) is a demyelinating disease of the CNS caused by reactivation of JC virus (JCV) in a setting of cellular immunosuppression. Originally, PML was observed in patients with advanced HIV infection, lymphoproliferative disorders and transplant recipients. However, the widespread use of HIV antiretroviral drugs and the new selective immunomodulatory and immunosuppressive medications, such as Rituximab and Natalizumab, has recently modified the epidemiology, clinical presentation and prognosis of PML. Herein, we discuss the new concepts on PML, emphasizing the recent modification in the epidemiology; the impact of new immunomodulatory treatments in the disease, PML-IRIS (Immune reconstitution inflammatory sindrome), new treatment strategies and other JCV related CNS diseases.
\end{abstract}

Keywords: leukoencephalopathy, natalizumab, JC virus.

\section{RESUMO}

A leucoencefalopatia multifocal progressiva (LMP) é uma doença desmielinizante do sistema nervoso central (SNC) causada pela reativação do vírus JC (JCV) em um ambiente de imunossupressão celular. Originalmente, LMP foi descrita em pacientes com infecção avançada pelo HIV, doenças linfoproliferativas e transplantados. No entanto, a utilização generalizada de anti-retrovirais para a infecção pelo HIV e novos imunomoduladores seletivos e imunossupressores, como Rituximab e Natalizumab, modificaram recentemente a epidemiologia, apresentação clínica e prognóstico da LMP. Neste artigo, vamos discutir os novos conceitos sobre LMP, enfatizando a recente modificação na epidemiologia, o impacto de novos tratamentos imunomoduladores na doença, síndrome inflamatória da reconstituição imune, novas estratégias de tratamento e outras doenças relacionadas ao JCV no SNC.

Palavras chave: leucoencefalopatia, natalizumab, virus JC.

Progressive multifocal leukoencephalopathy (PML) is a rare demyelinating disease of the CNS caused by reactivation of JC virus (JCV). Primary infection occurs in childhood and it is asymptomatic in most patients. Thereafter, the virus remains latent in the kidney, bone marrow and lymphoid organs, but, in a setting of cellular immunosuppression, the virus reactivates, spreads to the central nervous system (CNS), leading to infection of oligodendrocytes and demyelination ${ }^{1}$.

Most often, PML presents with motor deficits, visual disturbances and cognitive impairment, in a subacute evolution. On MRI, lesions are hyperintense on T2-weighted and Fluid attenuated inversion recovery (FLAIR) sequences and located predominantely in the subcortical white matter of the cerebral hemispheres and cerebellar peduncles². Originally, PML was observed in patients with advanced HIV infection, lymphoproliferative disorders and transplant recipients. However, the widespread use of HIV antiretroviral drugs and new selective immunomodulatory and immunosuppressive medications, such as Rituximab and Natalizumab, had recently modified the epidemiology, clinical presentation and prognosis of $\mathrm{PML}^{3}$.

Herein, we discuss the new concepts on PML, emphasizing the recent modification in the epidemiology, the impact of new immunomodulatory treatments in the disease, PMLIRIS, new treatment strategies and other JCV related CNS diseases.

\section{Epidemiology}

From the 1958 to 1980 `s, PML was observed mostly in patients being treated with corticosteroids and other immunosuppressive drugs, as well as individuals with hematological malignancies. A review of the literature in 1984 revealed only 230 cases, most of them associated with hematological diseases ${ }^{4}$. The emergence of AIDS changed the PML 
epidemiology. Its incidence increased 50-fold and HIV infection quickly became the leading predisposing condition for the development of disease ${ }^{1}$. In the pre-HAART era, up to $5 \%$ of HIV -infected individuals were diagnosed with PML and the median survival was only 6 months. Less than $10 \%$ were alive one year after the onset of symptoms ${ }^{5}$.

The introduction of more potent antiretroviral regimens led to a considerable decrease in its incidence and mortality in the last 17 years. Data from the Swiss cohort showed a decrease of the incidence from 0.24 cases per 100 patient-years before HAART era to 0.06 cases per 100 patient-years from 1996 on $^{6}$. However, some authors believe that the impact of HAART was less evident in PML incidence compared to other central nervous system opportunistic infections ${ }^{7}$. Since restoration of the cellular immune response against JCV is the best predictor of survival in $\mathrm{PML}^{8}$, the introduction of combined antiretroviral drugs led to a significant improvement in mortality. Worldwide, the one-year survival increased from $10 \%$ in the $1980-1990$ 's to around $50 \%$ nowadays ${ }^{1}$. Also important is the fact that more than half of the long-term PML survivors have no or only mild disability?.

More recently, the introduction of new immunomodulatory and immunosuppressive drugs (Table 1) in the treatment of tumors and autoimmune diseases expanded the spectrum of conditions associated with PML as described below ${ }^{1,10,11}$.

\section{PML and immunomodulatory drugs}

In the last years, several monoclonal antibodies and other particles designed to act on specific steps of the immune response have been designed and used in the treatment of malignancies and autoimmune diseases (multiple sclerosis, Crohn's disease, psoriasis, systemic erythematous lupus). The association between Rituximab, a humanized monoclonal antibody directed against the CD20 antigen on B-lymphocytes and PML was described more than ten years ago ${ }^{12}$, but it was only after the temporary withdrawn of Natalizumab, an anti- a4 integrin, from market in 2005 after three cases in Crohn's disease and multiple sclerosis patients, that a clear relationship between some immunomodulatory agents and the development of the disease was established ${ }^{13,14}$. Efalizumab, an antibody AntiCD1la used in the treatment of psoriasis was also withdrawn from market in 2009 due to its association with PML ${ }^{15}$.

Table 1. Immunomodulatory agents associated with PML.

\begin{tabular}{lc} 
Agent & Mechanism of action \\
\hline Natalizumab & Anti- a4 integrin \\
Rituximab & Anti-CD20 \\
Efalizumab & Anti-CD11a \\
& (a subunit of the beta 2 integrin LFA-1) \\
Adalimumab & Anti-TNF- $\alpha$ \\
Infliximab & Anti-TNF- $\alpha$ \\
Etarnecept & Anti-TNF- $\alpha$ \\
Ruxolitinib & Inhibitor of Janus kinases (JAKs) 1 and 2 \\
\hline
\end{tabular}

Natalizumab blocks the alpha-4 subunit integrin association with vascular receptors, limiting adhesion and transmigration of leukocytes. In multiple sclerosis, efficacy may be related to blockade of T-lymphocyte migration into the central nervous system ${ }^{16}$. On the other hand, immune surveillance performed by these cells against JCV and other virus may be impaired resulting in the development of PML.

Overall, the incidence of PML in Natalizumab-treated patients was estimated as 2.1/1000 patients ${ }^{17}$, but the risk depends on JCV serology status, duration of Natalizumab treatment and prior immunosuppressant use. While the risk was estimated as $0.09 / 1000$ or less in patients without JCV antibodies, it was 11.1/1000 in patients with JCV antibodies, previous use of immunosuppressants and exposure to Natalizumab $>24$ months.

Clinically, the development of PML in multiple sclerosis patients poses an additional difficulty in the diagnosis, since PML onset is frequently mistaken with MS exacerbation, stroke or other neurological condition ${ }^{18}$. Cognitive, language, motor and visual symptoms are commonly seen in this setting, with cognitive changes being more prominent, possibly because of the multifocal multiple sclerosis lesions already present in these patients ${ }^{1}$. While optic nerve or spinal cord lesion involvement is more suggestive of multiple sclerosis exacerbation and seizures were the presenting symptom of PML in several Natalizumab-treated patient, their occurrence should always raise suspicion of this condition. MRI findings in Natalizumab-associated PML are similar to classical PML except that contrast enhancement was more frequently observed at presentation ${ }^{18}$.

The first step in the treatment is to discontinue $\mathrm{Na}$ talizumab. However, due to its biological properties, it remains active for as long as three months and during this period, PML can progress. Empiric treatment with plasma exchange or immunoadsorption has been tried in an attempt to accelerate the elimination of the monoclonal antibody ${ }^{19}$. This approach frequently results, three to six weeks later, in the development of an intense IRIS due to the restoration of the lymphocyte trafficking into the central nervous system that can be fatal. Most of the reported patients who developed IRIS received high-dose glucocorticoids (dexamethasone or methylprednisolone) followed by a slow tapering in order to lessen the immune reconstitution and avoid additional damage ${ }^{18}$. There is evidence of a better survival in PML associated with Natalizumab use (70\%) compared to other conditions, but survivors may have a higher degree of disability $^{20}$.

\section{PML HIV-related IRIS}

IRIS is defined as a paradoxical worsening of preexisting infectious processes or development of new symptoms following the initiation of highly active antiretroviral therapy (HAART) in HIV-infected individuals. It usually follows the 
rapid restoration of the immune function and is often selflimited, but it can be fatal or associated with permanent sequelae. PML is one of the most frequent opportunist infections associated with IRIS and, in the HAART era, between 10 and $20 \%$ of the PML patients develop inflammatory manifestations $^{21}$. In a recent Brazilian series of HIV infected PML patients, the incidence was $6 \%{ }^{22}$. Clinical presentation is marked by a transient worsening or development of new neurological symptoms and, in severe cases, signs and symptoms of intracranial hypertension. Most often, PML-IRIS starts between three to six weeks after HAART is begun, but it has been described between 1 and 104 weeks ${ }^{1}$. Contrast enhancement and edema, denoting blood brain barrier disruption secondary to the inflammatory process, can be observed on MRI. Brain biopsy usually shows CD8+T lymphocyte infiltrates in areas of demyelination, which is different from classical PML where inflammatory infiltrates are mild or absent ${ }^{1,2}$.

In most cases, IRIS is a transient self-limited process and HAART should not be discontinued. However, there are reports of fatal outcome due to brain swelling and herniation. Corticosteroids have been used by several groups in order to modulate inflammatory reaction and avoid a catastrophic deterioration, but their use is controversial since they can also potentiate immunosuppression and blunt the JCV specific cellular immune response ${ }^{21}$. We believe that steroids should be reserved only for PML-IRIS patients with brain edema and risk of herniation.

Interestingly, the development of IRIS has no impact in the outcome of PML as observed in a recent study ${ }^{23}$.

\section{Treatment}

There are no specific antivirals drugs against JCV. Drugs such as cidofovir, cytarabine, topotecan and mefloquine were evaluated in several trials but results were disappointing and associated with serious adverse effects ${ }^{1,2}$.

There is evidence that JCV infects the cells trough the 5-HT2A serotonin receptor. Mirtazapine, an antidepressant that acts inhibiting this receptor has been used in treatment of PML. Although the concept sounds attractive and the drug is usually well tolerated, the evidence to date is scarce and based mostly in case reports and small series ${ }^{24}$. The benefit is modest at best, but it can be considered both in patients with and without HIV infection.

The increase in the PML survival rates observed over the last years resulted from the widespread use of HAART in HIV infected patients ${ }^{1-3}$. Restoration of the adaptive immune response is crucial in controlling JCV replication and stabilizing disease. Thus, the introduction of HAART in drug-naïve patients or a change in the antiretroviral regimen must be done after PML diagnosis. However, there is evidence that some antiretroviral classes may have an additional benefit over others. In a study with a cohort of 98 PML patients from Spain, the use of antiretroviral regimens containing protease inhibitors were associated with reduction in mortality ${ }^{25}$. Another interesting approach is to use an early-intensified antiretroviral combination with five drugs in order to quickly reduce the HIV load and restore JCV immune response. Gasnault et al studied 28 PML patients who received efavirenz, ritonavir-boosted lopinavir, and the fixed-dose emtricitabine- tenofovir combination for 12 months and enfuvirtide for the first six months ${ }^{26}$. The one-year survival was $75 \%$, which was better to previous observed but it was an open label non-comparative trial without a control group.

In other clinical scenarios (autoimmune diseases, post transplantation) where PML have been observed, an attempt to reduce or stop immunosuppressive drugs should be considered in an individual basis since it can restore the JCV specific immune response but also can result in a flare of an autoimmune disease or graft rejection ${ }^{1}$.

\section{Other JCV CNS related diseases}

Oligodendrocytes are the preferred CNS cells infected by JCV, leading to demyelination and PML. However, JCV has been also associated with other neurological diseases. A syndrome marked by progressive incoordination, dysarthria and cerebellar gait and atrophy of the cerebellum without white matter on MRI lesions occurs when a mutant virus with a 10 bp deletion in the $\mathrm{C}$ terminus of the VP1 capsid protein infects the granule cell neurons. JCV granule cell neuronopathy has been described in isolation or concomitant to PML ${ }^{27}$.

Rarely, JCV has been associated with meningitis and encephalitis $^{28,29}$. There are reports of JCV isolation in the CSF of immunocompetent and immunosuppressed patients with a meningeal syndrome and no focal symptoms ${ }^{28}$. The prevalence of JCV meningitis is not known but it is believed to be extremely low. The predominant involvement of the gray matter with limited demyelination by JCV results in an encephalopathy with progressive cognitive decline ${ }^{29}$. In all other JCV CNS related diseases, the rationale of treatment follows what is observed for PML: restore immune response trough HAART in HIV patients or discontinue immunosuppression whenever possible.

\section{References}

1. Tan CS, Koralnik IJ. Progressive multifocal leukoencephalopathy and other disorders caused by JC virus: clinical features and pathogenesis. Lancet Neurol 2010;9:425-437.
Bellizzi A, Anzivino E, Rodio DM, Palamara AT, Nencioni L, Pietropaolo V. New insights on human polyomavirus JC and pathogenesis of progressive multifocal leukoencephalopathy. Clin Dev Immunol 2013;2013:839719. 
3. Ferenczy MW, Marshall LJ, Nelson CD, et al. Molecular biology, epidemiology, and pathogenesis of progressive multifocal leukoencephalopathy, the JC virus-induced demyelinating disease of the human brain. Clin Microbiol Rev 2012;25:471-506.

4. Brooks BR, Walker DL. Progressive multifocal leukoencephalopathy. Neurol Clin 1984;2:299-313.

5. Berger JR, Pall L, Lanska D, Whiteman M. Progressive multifocal leukoencephalopathy in patients with HIV infection. J Neurovirol 1998; 4:59-68.

6. Khanna N, Elzi L, Mueller NJ, et al. Incidence and outcome of progressive multifocal leukoencephalopathy over 20 years of the Swiss HIV Cohort Study. Clin Infect Dis 2009;48:1459-1466.

7. Sacktor N. The epidemiology of human immunodeficiency virusassociated neurological disease in the era of highly active antiretroviral therapy. J Neurovirol 2002;8(Suppl 2):S115-S121.

8. Du Pasquier RA, Kuroda MJ, Zheng $Y$, et al. A prospective study demonstrates an association between JC virus-specific cytotoxic $T$ lymphocytes and the early control of progressive multifocal leukoencephalopathy. Brain 2004;127:1970-1978.

9. Lima MA, Bernal-Cano F, Clifford DB, et al. Clinical outcome of longterm survivors of progressive multifocal leukoencephalopathy. J Neurol Neurosurg Psych 2010;811288-1291.

10. Nakamichi K, Mizusawa H, Yamada M, et al. Characteristics of progressive multifocal leukoencephalopathy clarified through internet-assisted laboratory surveillance in Japan. BMC Neurol 2012;12:121.

11. Wathes R, Moule S, Milojkovic D. Progressive multifocal leukoencephalopathy associated with ruxolitinib. N Engl J Med 2013; 369:197-198.

12. Goldberg SL, Pecora AL, Alter RS, et al. Unusual viral infections (progressive multifocal leukoencephalopathy and cytomegalovirus disease) after high-dose chemotherapy with autologous blood stem cell rescue and peritransplantation rituximab. Blood 2002;99:1486-1488.

13. Langer-Gould A, Atlas SW, Green AJ, Bollen AW, Pelletier D. Progressive multifocal leukoencephalopathy in a patient treated with natalizumab. N Engl J Med 2005;353:375-381.

14. Van Assche G, Van Ranst M, Sciot R, et al. Progressive multifocal leukoencephalopathy after natalizumab therapy for Crohn's disease. N Engl J Med 2005;353:362-368.

15. Kothary N, Diak IL, Brinker A, Bezabeh S, Avigan M, Dal Pan G. Progressive multifocal leukoencephalopathy associated with efalizumab use in psoriasis patients. J Am Acad Dermatol 2011;65:546-551.

16. Rudick R, Polman C, Clifford D, Miller D, Steinman L. Natalizumab: bench to bedside and beyond. AMA Neurol 2013;70:172-182.
17. loomgren G, Richman S, Hotermans C, et al. Risk of natalizumabassociated progressive multifocal leukoencephalopathy. N Engl J Med 2012;366:1870-1880.

18. Clifford DB, De Luca A, Simpson DM, Arendt G, Giovannoni G, Nath A. Natalizumab-associated progressive multifocal leukoencephalopathy in patients with multiple sclerosis: lessons from 28 cases. Lancet Neurol 2010;9:438-446.

19. Wenning W, Haghikia A, Laubenberger J, et al. Treatment of progressive multifocal leukoencephalopathy associated with natalizumab. N Engl J Med 2009;361:1075-1080.

20. Dahlhaus S, Hoepner R, Chan A, et al. Disease course and outcome of 15 monocentrically treated natalizumab-associated progressive multifocal leukoencephalopathy patients. J Neurol Neurosurg Psych 2013 Apr 19. [Epub ahead of print]

21. Tan K, Roda R, Ostrow L, McArthur J, Nath A. PML-IRIS in patients with HIV infection: clinical manifestations and treatment with steroids. Neurology 2009;72:1458-1464.

22. Piza F, Fink MC, Nogueira GS, Pannuti CS, Oliveira AC, Vidal JE. JC virus-associated central nervous system diseases in HIV-infected patients in Brazil: clinical presentations, associated factors with mortality and outcome. Braz J linfect Dis 2012;16:153-156.

23. Marzocchetti A, Tompkins T, Clifford DB, et al. Determinants of survival in progressive multifocal leukoencephalopathy. Neurology 2009;73:1551-1558.

24. Cettomai D, McArthur JC. Mirtazapine use in human immunodeficiency virus-infected patients with progressive multifocal leukoencephalopathy. Arch Neurol 2009;66:255-258.

25. Fanjul F, Riveiro-Barciela M, GonzalezJ, et al. Evaluation of progressive multifocal leukoencephalopathy treatments in a Spanish cohort of HIV-infected patients: do protease inhibitors improve survival regardless of central nervous system penetration-effectiveness (CPE) score? HIV Med 2013;14:321-325.

26. Gasnault J, Costagliola D, Hendel-Chavez H, et al. Improved survival of HIV-1-infected patients with progressive multifocal leukoencephalopathy receiving early 5-drug combination antiretroviral therapy. PLoS One 2011;6:e20967.

27. Koralnik IJ, Wüthrich C, Dang X, et al. JC virus granule cell neuronopathy: A novel clinical syndrome distinct from progressive multifocal leukoencephalopathy. Ann Neurol 2005;57:576-580.

28. Viallard JF, Ellie E, Lazaro E, Lafon ME, Pellegrin JL.JC virus meningitis in a patient with systemic lupus erythematosus. Lupus 2005; 14:964-966.

29. Dang X, Wüthrich C, Gordon J, Sawa H, Koralnik IJ. JC virus encephalopathy is associated with a novel agnoprotein-deletion JCV variant. PLoS One 2012;7:e35793. 